\title{
Impact of small cell user density on performance of small cells sleeping technique for HetNet
}

\author{
HetNet için küçük hücre kullanıcı yoğunluğunun küçük hücre uyutma \\ tekniği performansı üzerindeki etkisi
}

\author{
Sultan ALDIRMAZ ÇOLAK ${ }^{+}$(iD) \\ 1Electronics and Communication Engineering, Engineering Faculty, Kocaeli University, Kocaeli, Turkey. \\ sultanaldirmaz@kocaeli.edu.tr
}

Received/Geliș Tarihi: 13.04.2018, Accepted/Kabul Tarihi: 16.08.2018

* Corresponding author/Yazışılan Yazar

doi: $10.5505 /$ pajes.2018.73468 Research Article/Araștırma Makalesi

\begin{abstract}
In this paper, we analyze the impact of the small cell user density on the power consumption and the number of served users by the macro cell and small cells. It is assumed that users are distributed uniformly in all coverage area with different density and small cell user density is related linearly with macro cell user density. In the simulations, three different mean values are chosen, where the power consumption and the number of served users by the macro cell and small cells are investigated according to these values. The simulation results show that small cells with low mean value enable to save more power. When user density of macro cell is $\lambda_{0}=5 \times 10^{-4}$ and mean value of small cell user density equals to 15, saved power by using the small cells sleeping technique is 695 Watts. When $\lambda_{0}=10 \times 10^{-4}$ this saved power decreases to 372 Watts. Similarly, as the mean value of the small cell user density increases, the power gain obtained by the algorithm decreases.
\end{abstract}

Keywords: Heterogeneous network, Macro cell, Small cell, Traffic offloading, User density

\section{Introduction}

While total mobile data traffic was 45 million terabytes (TB) in 2012, this traffic is expected to reach 623 million TB until 2020 [1]. It is clear that this forecast seems to be very realistic, since many devices are expected to join the network due to the emerging internet of things (IoT) technologies. One other important forecast is that, nearly $2 \%$ of global $\mathrm{CO}_{2}$ emissions are expected to be produced by the information and communication technology and the mobile communication industries by 2020 [2]. To reduce the amount of $\mathrm{CO}_{2}$ emissions, we need to reduce the amount of power consumed by so many devices. Therefore, many researchers study on energy efficient systems including green communication and massive multiinput multi output (MIMO). Besides meeting overwhelming traffic demands, worldwide network operators agree that they have to manage their cellular networks' energy efficiency and reduce $\mathrm{CO}_{2}$ emission.

The celebrated Shannon-Hartley capacity equation states that, the data rate depends on bandwidth and the signal to noise ratio (SNR). In cellular communication systems, signal to interference plus noise ratio (SINR) is used instead of SNR. While the desired signal strength decreases as the user moves away from the base station (BS), the interference signals from other cells gradually increase. This fact causes degradation of the SINR and therefore, the data rate provided by the base

\begin{abstract}
Öz
Bu çalışmada, küçük hücre kullanıcı yoğunluğunun güç tüketimi ve makro ve küçük hücreler tarafindan servis verilen kullanıcı sayısı üzerindeki etkisi analiz edilmektedir. Kullanıcıların tüm kapsama alanında düzgün dağılımlı olarak konumlandığı ve küçük hücre kullanıcı yoğunluğunun makro hücre kullanıcı yoğunluğu ile doğrusal olarak ilișkili olduğu varsayılmıștır. Benzetimlerde, üç farklı ortalama değer seçilmiș ve bu değerlere göre güç tüketimi ve makro hücre ve küçük hücreler tarafından servis verilen kullanıcı sayısı incelenmiştir. Benzetim sonuçları, düşük ortalama değere sahip küçük hücrelerin yüksek tasarruf gücü sağladığını göstermektedir. Makro hücrenin kullanıcl yoğunluğu $\lambda_{0}=5 \times 10^{-4}$ ve küçük hücre kullanıcl yoğunluğunun ortalama değeri 15 olduğunda, küçük hücre uyutma tekniği kullanılarak elde edilen kazanç 695 Watt'tır. $\lambda_{0}=10 \times 10^{-4}$ olduğunda ise 372 Watt'a düșmektedir. Benzer olarak küçük hücre kullanıcı yoğunluğunun ortalama değeri arttıkça algoritma ile elde edilen güç kazancı azalmaktadır.
\end{abstract}

Anhtar kelimeler: Heterojen ağlar, Kullanıcı yoğunluğu, Küçük Hücre, Makro hücre, Trafik aktarımı station decreases. Since the SINR value of the received signal at edge of the cells may have a low value, to provide a good coverage and to increase data rate, low-power small cells (SCs) can be placed in these regions. In this manner, heterogeneous networks (HetNet) are constituted and they not only provide coverage for smaller area which has high user density, but also provide high data rate for users in this area [3],[4].HetNets are increasingly attracting attention due to their capability of supplying high data rates everywhere and all times demanded by the users with lower $\mathrm{CO}_{2}$ emissions [1]-[3],[5]-[10]. Small BSs (SBSs) are responsible for providing good coverage where the population is high, such as malls, coffee shops, and airports with reduced power consumption. Small cells are especially more functional when employed in places where the fluctuation in the population is very high, such as stadiums, concert halls, and theaters. The users can be offloaded from LTE system to Wi-Fi according to the number of traffic load. However, since the number of users to be served by a SBS is limited, more than a certain number of users should still receive service from the macro BS (MBS). In a highly populated region, users can be offloaded from the MBS to an SBS, if this SBS is in sleeping mode. This process is called as traffic offloading. HetNets are favored due to their properties of providing energy efficiency (EE) by using low-powered nodes and traffic offloading.

In Europe, approximate power consumption of a typical MBS and a typical SBS is $930 \mathrm{~W}$ and $10 \mathrm{~W}$, respectively [1]. Since the 
power consumption of, for example, a hundred active SBS is much higher than a single MBS, usage of a hundred SBSs in a heterogeneous network does not provide energy efficiency. Therefore, to obtain energy efficiency in network densification scheme, SCs should be activated (active or sleep mode) carefully by observing heterogeneous network. Recently, many attention has been directed towards this problem [11]-[14]. In the SBS activation process, algorithms should consider the interference from SBSs to MBS. In order to reduce this interference some processing should be applied, such as using different frequency bands in small and MCs, or using interference excision algorithms at the receiver at the expense of increased receiver complexity. In the literature, it is assumed that an MBS, which is placed in the center of the cell, is always active in the heterogeneous network and responsible of minimizing the interference which SBS generates.

Recently, an outstanding paper is proposed small cell activation in order to reduce HetNet power consumptions for uniform and non-uniform user distribution [13]. In this paper, power consumption of MC, SC and HetNet are calculated with respect to MC user density. The authors of [13] introduced two different algorithms to dynamically changing SBSs' operation modes. However, they do not take into account that an SC can served only a limited number of users. In a recent paper, [14], three different algorithms that evaluate the power usage of HetNets in the case of activated SBSs by taking the SC's limited user case are proposed, which further improve the results presented in [13]. Furthermore, the algorithms presented in [14] have lower computational complexity than that of [13]. In [13], the SBS switching mode algorithm is based on distance between MBS and SBSs, and user density of SCs. However, in [14], it includes a hybrid algorithm as well as those. Another remarkable study [15] investigates the base station (BS) density for homogeneous and HetNet scenarios with the sleeping strategy in order to improve EE. The authors assume that the BS enters the sleeping mode if there is no user in BS coverage area. According to this sleeping strategy, they derive BS activation probabilities and the coverage probabilities for different pico-BS density [15]. They also show that the upper bound of the EE is independent of user density. The authors assumed that SC user density varies uniformly with MC user density with a single mean value of SC user density. However, to the best of our knowledge, there are no studies which investigate SC user density impact on the number of users served by MC and SCs. In this paper, we evaluate the performance of the power consumption of SBS, MBS and HetNet for uniform user distribution with different mean values. Furthermore, the variation on number of users who are taken service from SC and MC with different user density is analyzed by taking into account traffic offloading. The main contributions of the paper are summarized as follows:

- We assume that number of users served by SC is limited as in practical case,

- The features of user distribution, i.e., mean and variance of the traffic, are taken into account while calculating the power consumption,

- Power consumption is analyzed whether the proposed algorithm in [14] is used or not.

The paper is organized as follows. In Section 2, the heterogeneous network model and its power consumption are discussed. Section 3 gives a short overview about SC activation algorithm which is used throughout the paper. Section 4 presents computer simulation results. Finally, our paper concludes in Section 5.

\section{System model}

In this section, the system model is introduced first, and then network traffic load based power consumption expressions are derived.

\section{$2.1 \quad$ Network model}

The proposed heterogeneous network model is shown in Figure 1. According to this model, an MBS is placed in the center of the cell. Along with the MBS, the cell also includes $M$ SBSs to provide coverage. These SBSs can be operated in active or sleep mode depending on traffic load of the considered cell. If an SBS is operated in sleep mode, user equipment (UE) can be served by the MBS; otherwise it can be served by an SBS. The MBS should be always active at all time and behave as an umbrella in order to provide coverage in the whole cell area. Moreover, the MBS should be responsible for controlling of all SBSs and minimizing the interference.

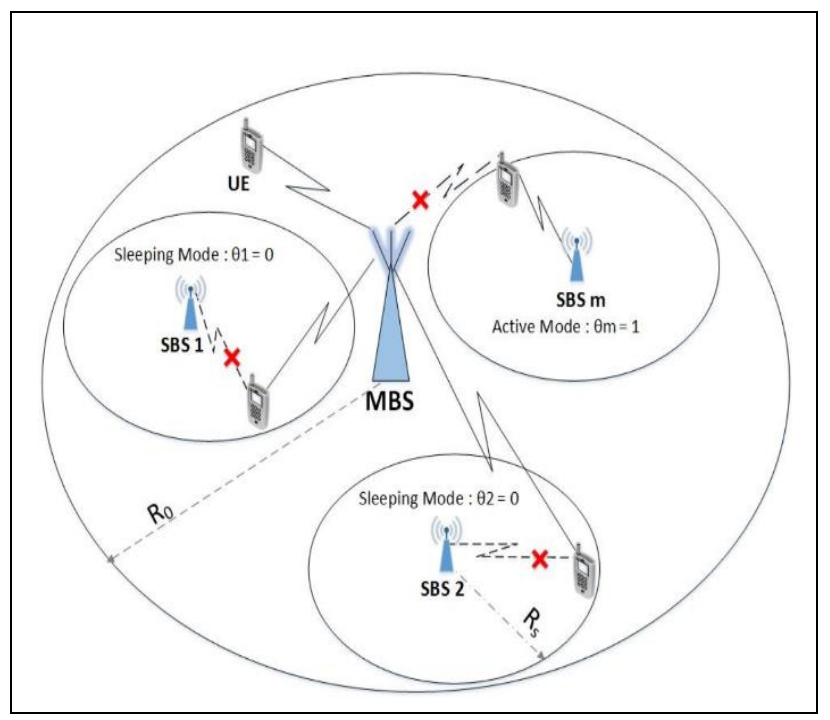

Figure 1: HetNet system model.

Let all of the SBSs be element of the set $\mathcal{M}=\{1,2,3, \ldots, \mathrm{M}\}$, where the vector $\boldsymbol{\theta}=\left[\theta_{1}, \theta_{2}, \ldots, \theta_{M}\right]$ indicates their operation mode (active or sleep). If the $m$-th SBS is in active mode, then $\theta_{m}=1$, otherwise $\theta_{m}=0$. Let us also assume $K$ be the number of active users who receive service from the MBS, where $K$ can be modelled by a Poission distributed random variable with its mean $\mu=\lambda_{0}\left\|A_{0}\right\|+\sum_{\left\{m \mid \theta_{m}=0\right\}} \lambda_{m}\left\|A_{m}\right\|$. Here, $A_{0}$ and $A_{m}$ denote coverage areas of entire area outside from all active SBSs and SCs areas, respectively. Also, $\lambda_{0}$ and $\lambda_{m}$ are user density of the MC and $m$ th SC. According to our system model, $\lambda_{m}$ is modelled as a uniform random variable that depends on $\lambda_{0}$.

Figure 2 shows probability distribution function (pdf) of user density of an SC. Expected value of an SC user distribution, which obeys the uniform distribution, is given by $\mathrm{Eq}(1)$.

$$
E\left[\lambda_{m}\right]=\int_{a}^{b} \lambda_{m} p\left(\lambda_{m}\right) d \lambda_{m},
$$

Where $a$ and $b$ are $\left(\mu-\sqrt{\frac{\mu}{3}}\right) \times \lambda_{0}$ and $\left(\mu+\sqrt{\frac{\mu}{3}}\right) \times \lambda_{0}$, respectively. 


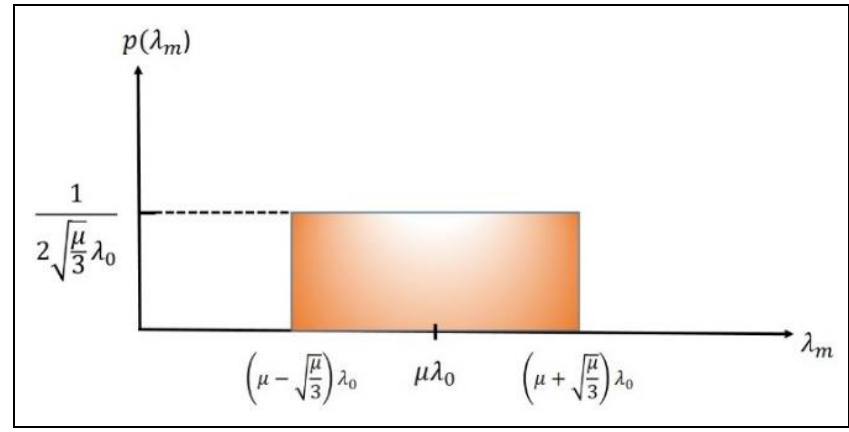

Figure 2: Probability distribution function of user density of an SC.

\subsection{Power consumption model}

The power consumption characteristics of an MC and an SC differ greatly. Lower band of power consumption $(\underline{P})$ of an MBS is 712 Watts [1],[13]. This value increases exponentially with the traffic load of the cell. However, an SBS only consumes 10 Watts if it operates in active mode, whereas if it is in sleep mode, it consumes 3 Watts. Unlike the MBS, it is assumed in the literature that the power consumption of an SBS is independent of the traffic load, since the coverage area of the SC is very small compared that of the MBS. Therefore, by offloading MC users in areas, which have high traffic load, to SCs, it is possible to save power.

The power consumption of an MBS can be written as a function of the traffic load by Eq (2).

$$
P=\underline{P}+u P^{t}(\boldsymbol{\theta}),
$$

Where $u$ denotes the power utilization coefficient and $P^{t}(\boldsymbol{\theta})$ is the transmit power which is related to traffic load of the macro BS and the switched off small BSs. Similarly, power consumption of an SBS can be expressed by Eq (3).

$p=\left\{\begin{array}{c}p_{1}=\underline{p}+v p^{t}, \theta_{m}=1 \text { (Active mode) } \\ p_{0}, \quad \theta_{m}=0 \quad \text { (Sleep mode) }\end{array} \forall m \in \mathrm{M}\right.$,

where $p_{1}$ and $p_{0}$ represent the power consumption of active mode and sleep modes, respectively. $M$ denotes the maximum number of SCs and $v$ is the power utilization coefficient of an SBS. Thus, total power consumption of a HetNet is modelled by $\mathrm{Eq}(4)$.

$$
P^{H e t}(\boldsymbol{\theta})=\underline{P}+u P^{t}(\boldsymbol{\theta})+M p_{0}+H(\boldsymbol{\theta}) \Delta p,
$$

Where $H(\boldsymbol{\theta})$ shows the number of active SBSs in the network, and $\Delta p=p_{1}-p_{0}$ represents the power consumption difference between the active and sleep modes. According to [11], to ensure the desired quality of service (QoS) for user $k$, the required MBS transmit power depends on the number of the users in the network $(K)$, desired data rate $(b)$, bandwidth of the system $(B W)$, and the noise power $\left(N_{0}\right)$. The required MBS transmit power can be calculated by Eq (5)[11].

$$
= \begin{cases}\frac{\Gamma N_{0} B W}{-D \ln (1-\varepsilon)} \times \frac{2^{\frac{K b}{B W}}-1}{K}, & r_{k}<r_{0}, \\ \frac{\Gamma N_{0} B W}{-D \ln (1-\varepsilon)} \times \frac{2^{\frac{K b}{B W}}-1}{K} \times\left(\frac{r_{k}}{r_{0}}\right)^{a}, & \text { otherwise, }\end{cases}
$$

Where $\Gamma \geq 1$ denotes loss of capacity due to modulation and coding. $r_{k}$ and $r_{0}$ indicate the distance from user $k$ to the MBS and the reference distance which is used for path loss model. $\varepsilon$ denotes the outage probability and $\mathrm{D}$ is the reference path loss. The received power decreases by a fixed path loss $(D>0)$. It can be seen from Eq (5) that the power consumption $\left(P_{k}^{t}\right)$ increases with the traffic load, depending on the number of users $(K)$. Since $K$ is a random variable, $P_{k}^{t}$ is also a random variable and its expected value $\left(P^{t}(\boldsymbol{\theta})\right)$ should be calculated by taking $K$ and $r_{k}$ into account.

In [11] and [13], it is stated that $P^{t}(\boldsymbol{\theta})$ equals to the product of traffic load $T(\boldsymbol{\theta})$, where all coverage region exclude all active SCs, and average transmit power of a MBS per user, Z( $\boldsymbol{\theta}) . T(\boldsymbol{\theta})$ and $\mathrm{Z}(\boldsymbol{\theta})$ are expressed by Eq (6) and Eq (7);

$$
\begin{gathered}
T(\boldsymbol{\theta})=\frac{\Gamma N_{0} B W}{-D \ln (1-\varepsilon)}\left[\exp \left[\left(2^{\frac{b}{B W}}-1\right)(K)\right]-1\right], \\
Z(\boldsymbol{\theta})=\frac{\frac{2 \pi \lambda_{0}}{a+2}\left(R_{0}^{a+2}+\frac{a r_{0}^{a+2}}{2}\right)-\lambda_{0} \sum_{m=1}^{M} \lambda_{m} \pi R_{S}^{2} d_{m}^{a}}{r_{0}^{a} \mathrm{~K}} \\
+\frac{\sum_{\left\{m \mid \theta_{m}=0\right\}} \lambda_{m} \pi R_{s}^{2} d_{m}^{a}}{r_{0}^{a} \mathrm{~K}} \\
+\frac{\sum_{\left\{\left\{m \mid \theta_{m}=1\right\} \cap\left(A_{m} \lambda_{m}>F_{\max }\right)\right\}}\left(\lambda_{m} \pi R_{s}^{2}-F_{\max }\right) d_{m}^{a}}{r_{0}^{a} \mathrm{~K}} .
\end{gathered}
$$

In [13], the authors assume that $K=\lambda_{0} \pi R_{0}^{2}-\lambda_{0} M \pi R_{s}^{2}+$ $\sum_{\left\{m \mid \theta_{m}=0\right\}} \lambda_{m} \pi R_{s}^{2}$. However, they do not take into account the maximum number of users for which an SC can serve. As there is a limit on number of users served by an SC $\left(F_{\max }\right)$ in a realistic scenario, some users in the SC coverage area, should take service from the MC. Therefore, unlike the scenario considered in [13], the authors in [14] modified the number of users who receive service from the $\mathrm{MC}$ is expressed by Eq (8).

$$
\begin{gathered}
K=\lambda_{0} \pi R_{0}^{2}-\lambda_{0} M \pi R_{s}^{2}+\sum_{\left\{m \mid \theta_{m}=0\right\}} \lambda_{m} \pi R_{S}^{2} \\
+\sum_{\left\{\left(m \mid \theta_{m}=1\right) \cap\left(A_{m} \lambda_{m}>F_{\max }\right)\right\}}\left(\lambda_{m} \pi R_{S}^{2}-F_{\text {max }}\right) .
\end{gathered}
$$

It is clear that $K$ depends on not only cell area of MC and SCs, but also operation modes of SBSs. Moreover, $K$ in [14] includes users who are in the SC's coverage area whom they do not take service from the SC due to limit on number of users of SC.

\section{Small cell activation algorithm}

In [14], authors have proposed three different algorithms which decide SC operation mode in the HetNets in order to provide saved power. The algorithms' criteria are enumerated below:

a. Algorithm 1 is based on distance between the SC and the MC,

b. Algorithm 2 is based on density of the SC,

c. Algorithm 3 is based on a hybrid algorithm considers both listed above.

In [14], Algorithm 3 is shown as the optimum algorithm among them. For this reason, in this paper, Algorithm 3 will be used in the analyses, whose computational complexity equals to $O\left(M^{2}\right)$ which is lower than that of [13]. This algorithm uses Eqs. (2)-(9) in order to activate SBS gradually and calculate power consumption. For further details on this topic, the interested 
readers are referred [13]-[14],[16]. According to the algorithm, the saved power for all SCs are calculated iteratively and it is decided to close the SC which provides the highest power gain. The randomness of the SBS user density $\lambda_{m}$ and the distance between $S B S_{m}$ and the MBS, $d_{m}$, are taken into account throughout this calculation. For example, we consider two different SCs $S B S_{m}$ and $S B S_{n}$ with user densities $\lambda_{m}$ and $\lambda_{n}$ and their distances from the MBS $d_{m}$ and $d_{n}$, respectively. First, the algorithm sorts SCs according to user density in increasing order. Then, the system decides which SBS will be operated in active or sleep mode, taking into account of their potential saved power.

\section{Simulation results}

In this section, power consumption of HetNet is investigated under different densities of SC. Throughout the simulations, we model user positions in the MC and SCs as uniformly distributed. In this paper, because we only focus on the effect of $\mathrm{SC}$ user density on the power consumption and the number of served users by the MC and SCs, we assume that none of SC area is overlapped to another's. Therefore we can ignore the resultant interference. We also assume that the density of SC is always greater than that of MC $\left(\lambda_{m}>\lambda_{0}\right)$. This assumption is applicable to crowded and large places, including airports, malls, and concert halls. We also follow [17] to consider a practical range for $\lambda_{0}$. For further details on this topic, the interested readers are referred to [18],[19]. All system variables, which are taken from [13], are listed in Table 1.

Table 1: Meaning of parameters and symbols [13].

\begin{tabular}{cc}
\hline Parameters & Values \\
\hline MC radius, $R_{0}$ & $500 \mathrm{~m}$ \\
SC radius, $R_{S}$ & $10 \mathrm{~m}$ \\
Bandwidth of an MC, $B W$ & $10 \mathrm{MHz}$ \\
Each user's required data rate, $b$ & $0.1 \mathrm{Mbit} / \mathrm{sec}$ \\
Maximum allowable outage & 0.05 \\
probability, $\varepsilon$ & $1 \mathrm{~m}$ \\
Reference distance in channel model, $r_{0}$ & $-35 \mathrm{~dB}$ \\
Reference path loss, $D$ & 2.5 \\
Path loss exponent, $a$ & $\pi \times R_{S}^{2} \mathrm{~m}^{2}$ \\
Coverage area of an SC, $A_{m}$ & $\pi \times\left(R_{0}^{2}-R_{S}^{2}\right) \mathrm{m}^{2}$ \\
Area outside of all active SCs, $A_{0}$ & $0.1 \rightarrow 2] \times$ \\
User density in $A_{0}, \lambda_{0}$ & $10^{-3} \mathrm{user} / \mathrm{m}^{2}$ \\
The maximum transmit power of a & $40 \mathrm{Watts}$ \\
macro BS, $P_{\text {max }}^{t}$ & \\
Base power level of power & $712 \mathrm{Watts}$ \\
consumption of macro BS, $\underline{P}$ & \\
Power consumption of an SC in & $3 \mathrm{Watts}$ \\
sleeping mode, $p_{0}$ & $10 \mathrm{Watts}$ \\
Bower consumption of an SC in active $u$ & 14.5 \\
mode, $p_{1}$ & \\
Capacity loss, $\Gamma$ & \\
Noise power, $N_{0}$ & \\
Power utilization coefficient for macro & \\
\hline
\end{tabular}

Figure 3 plots the total number of users served by the HetNet with respect to the MC user density. Three different mean $(\mu)$ values are chosen for the SC user distribution in order to investigate variation of number of HetNet users. As seen from Figure 3, the number of users, that a HetNet can support, varies with the average value of $\lambda_{0}$. For example, when $\lambda_{0}=0.8 \times 10^{-3}$ and $\mu=75$, the maximum number of users, that a HetNet can support, equals to 2488 . Even if $\lambda_{0}$ is greater than this value, the network cannot provide service for more than 2488 users. Likewise, when $\mu=15$, the maximum number of users that the system can support is 2079 . This value is reached when $\lambda_{0}=1.7 \times 10^{-3}$. The number of users in the HetNet is given here, and this number is not related to the use of the proposed algorithm. The number of users supported by SCs, MC and HetNet with respect to $\lambda_{0}$ are comparatively given in Figure 4 . Figure 4 shows the number of served users by MC, SCs and HetNet which are generated by the considered algorithm using Eqs (2)-(9). In fact, the number of HetNet users can be found by summing up the number of MC users and SCs users. In this analysis $\mu$ and $M$ are chosen as 50 and 100, respectively. In Figure 4, while solid red and green lines represent the number of users of MC and 100 SCs when the proposed algorithm is used, dotted lines of them represent the number of users of MC and SCs when the proposed algorithm is not used. Black line denotes the number of users in the HetNet coverage area, which is summation of number of users in MC and SCs.

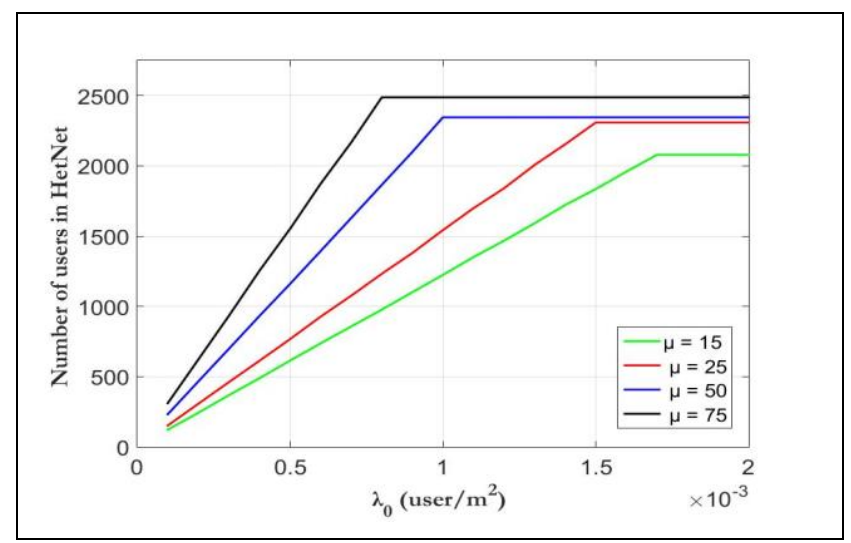

Figure 3: Variation of the number of users in the HetNet for user density of the MBS.

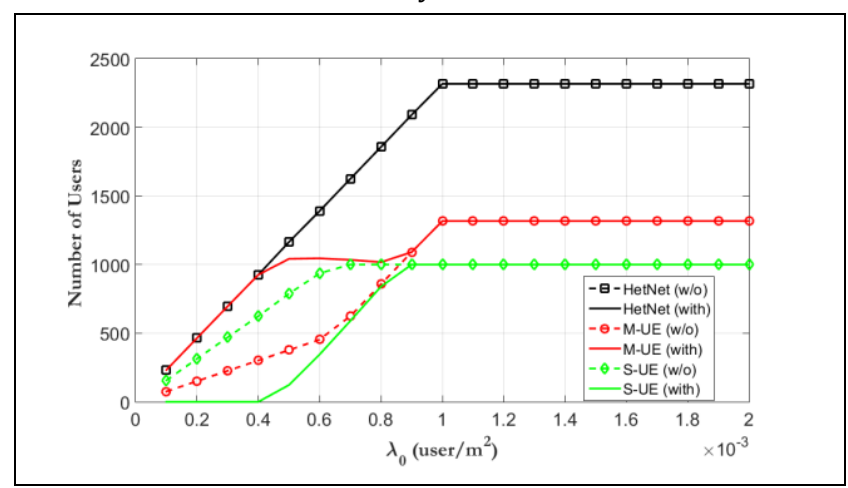

Figure 4: Variation of the number of users in a HetNet where the proposed algorithm is used and not used (M-UE: UE in the MC, S-UE: UE in the SCs, HetNet-UE :UE in the HetNet, (w/o) and (with) mean that when the proposed algorithm is not used and used ( $\mu=50, M=100)$.

As the user density increases, SCs save considerable power according to the algorithm when gradually activated. In this analysis, $\mu$ is chosen as 50 . We have assumed that each SBS can serve only a limited number of maximum 10 users $\left(F_{\max }\right)$. If an SC has more than 10 users, the remaining users should take 
service from the MBS. When the proposed algorithm is not used, each SC operates in active mode even if it has only one user. As seen in Figure 4, in case the algorithm is used, SCs are not activated until $\lambda_{0}<0.4 \times 10^{-3}$. On the other hand, if the algorithm is not used, SCs are activated linearly.

Since all SCs are operated in active mode beyond $\lambda_{0}=$ $0.9 \times 10^{-3}$, solid and dotted curves for red and green lines are converged. Besides, red and green lines with different markers are ovelapped at a certain $\lambda_{0}$ value. The overlap means that all SBS in the HetNet are opareted in active mode at $\lambda_{0}$. Thus, at a value greater than $\lambda_{0}$, SBS reaches its maximum number of users which it can serve, and beyond this value it can not serve more users anymore.

The number of users in the HetNet can be calculated by Eq (9),

$$
=\left\{\begin{array}{cc}
K_{\text {HetNet }} & \\
M F_{\text {max }}+\lambda_{0} \mathrm{~A}_{0}+\mathrm{M}\left(\lambda_{\mathrm{s}} \mathrm{A}_{\mathrm{s}}-\mathrm{F}_{\text {max }}\right), & \lambda_{\mathrm{s}} \mathrm{A}_{\mathrm{s}}>\mathrm{F}_{\text {max }} \\
M F_{\text {max }}+\lambda_{0} \mathrm{~A}_{0}+\mathrm{M} \lambda_{\mathrm{s}} \mathrm{A}_{\mathrm{s}}, & \lambda_{\mathrm{s}} \mathrm{A}_{\mathrm{s}}<\mathrm{F}_{\text {max }}
\end{array} .\right.
$$

The power consumption of HetNet is evaluated and the result is shown in Figure 5 as a function of user density. As the user density of SCs increases, power consumption also increases, because all SCs are activated faster. The lowest user density is plotted with green line, which has the lowest mean value. The power consumption reaches its maximum at $\lambda_{0}=1.7 \times 10^{-3}$. In other words, SCs are activated slowly with $\lambda_{0}$. The reason for reaching the same power consumption for all lines is that at their saturation point, all SCs are activated. When all of the SCs are operated in active mode, the total power of HetNet is calculated as $P_{t}=712 \mathrm{Watts}+14.5 \times 40$ Watts $+100 \times$ 10 Watts $=2292$ Watts. When all SCs are operated in active mode (saturation point), HetNet operates at its maximum capacity. We note that all lines in the simulation denote SC user density with different mean values $\left(\lambda_{m}=\left(\mu \pm \sqrt{\frac{\mu}{3}}\right) \lambda_{0}\right)$, and thus they reach their maximum value at different $\lambda_{0}$ values $\left(\lambda_{0, \text { max }}\right)$. Beyond $\lambda_{0, \text { max }}$, the HetNet can not serve more users.

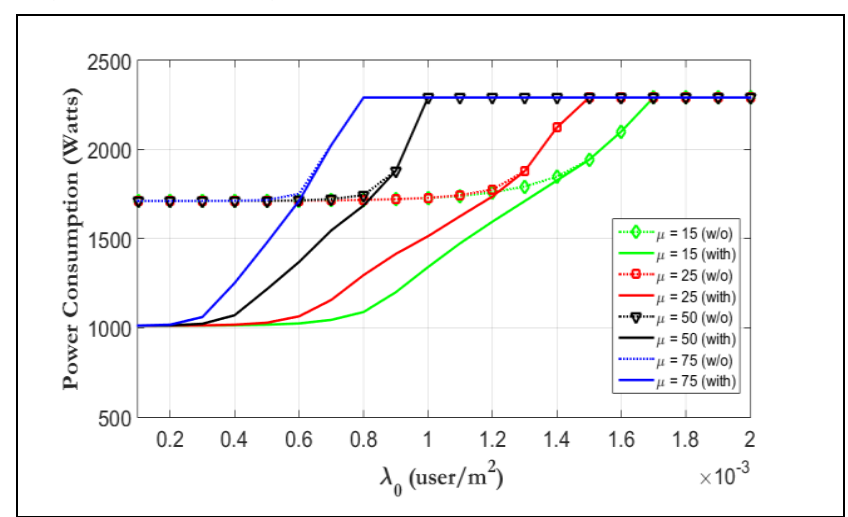

Figure 5: HetNet power consumption w.r.t the MC user density $((\mathrm{w} / \mathrm{o})$ and (with) mean that when the proposed algorithm is not used and used).

Finally, Figure 6 shows the HetNet power consumption with different mean values of SC user density in the network for the case where the algorithm is used and not used. In this analysis, user density of the MC is selected as $\lambda_{0}=5 \times 10^{-4}$ and $10^{-3}$. When $\lambda_{0}=10 \times 10^{-4}$, all SCs are activated in the highest mean value case. Thus, the power consumption is equal (there is no saved power) to each other where the algorithm is used or not used. In the other cases, especially for $\lambda_{0}=5 \times 10^{-4}$, the saved power is 695 Watts when $\mu=15$. Likewise, when $\lambda_{0}=10 \times 10^{-4}$, the saved power is 372 Watts. Thus, when $\lambda_{0}$ increases, saved power decreases.

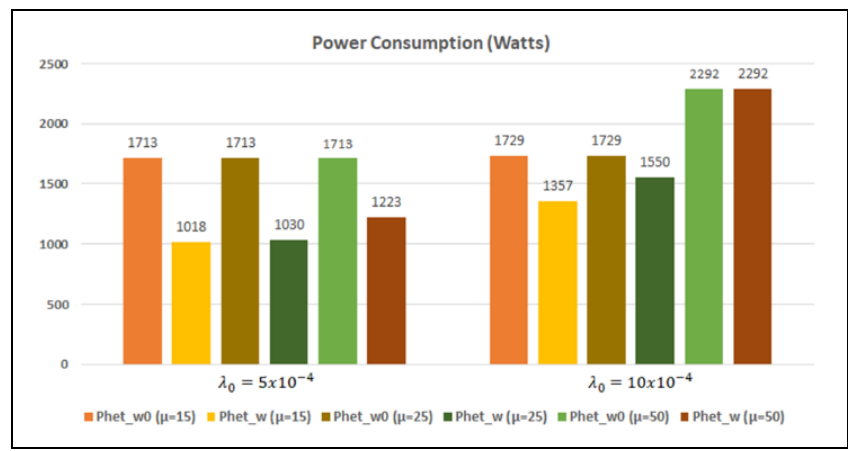

Figure 6: Power consumption of the HetNet vs. the MC user density ((w/o) and (with) mean that when the proposed algorithm is not used and used).

\section{Conclusions}

In this paper, we have considered SC user density variation impact on HetNet power consumption. We have assumed that the heterogeneous network has an MBS in the center of the cell and it contains $M$ SBSs. In order to save the power, SCs are gradually activated according to traffic load of the HetNet. Due to traffic offloading from MC to SCs, the system does not only save power but also it can serve more UEs.

According to simulation results, as the user density of SCs increases, system gets saturated faster. It is also seen that when the traffic load $\left(\lambda_{0}\right)$ of the MC increases, it leads to a faster network saturation. Then the cell reaches saturation and cannot serve more users. When UEs are placed in some specific regions, a few of the SCs can be activated, thus more power is saved. Simulation results indicate that when user density of macro cell increases twice, saved power by using the small cells sleeping technique decreases by half for $\mu=15$. Similarly, as the mean value of the small cell user density increases, the power gain obtained by the algorithm also decreases. In other words, the sleeping algorithm can be implemented effectively when the below conditions are fulfilled:

- When the MC user distribution is low $\left(\lambda_{0}<0.8 \times 10^{-3}\right)$, more power is saved (Figure 4),

- When the mean value of SC user distribution is low, more power is saved (Figure 5, Figure 6).

When the majority of SCs do not have very high user density, only a few SC can be activated, thus more power is saved.

\section{References}

[1] Auer G, Blume O, Giannini V, Godor I, Imran MA, Jading Y, Katranaras E, Olsson M, Sabella D, Skillermark P, Wajda W. "Earth project d2.3-energy efficiency analysis of the reference systems, areas of improvements and target breakdown". Energy Aware Radio Network Technology (EARTH), 7, 1-68, 2012.

[2] Webb M. "SMART 2020: Enabling the low carbon economy in the information age". The Climate Group. London, England, 2008. 
[3] Saker L, Elayoubi SE, Chahed T, Gati A. "Energy efficiency and capacity of heterogeneous network deployment in LTE-Advanced". European Wireless 2012; 18th European Wireless Conference 2012, Poznan, Poland, 18-20 April 2012.

[4] Zhang H, Chu X, Guo W and Wang S. "Coexistence of Wi-Fi and heterogeneous SC networks sharing unlicensed spectrum". IEEE Communications Magazine, 53(3), 158-164, 2015.

[5] Hwang I, Song B, Soliman SS. "A holistic view on hyper-dense heterogeneous and SC networks". IEEE Communication Magazine, 51(6), 20-27, 2013.

[6] Ge X, Tu S, Mao G, Wang CX, Han T. "5G ultra-dense cellular networks". IEEE Wireless Communications, 23(1), 72-79, 2016.

[7] Bhushan N, Li J, Malladi D, Gilmore R, Brenner D, Damnjanovic A, Sukhavasi R, Patel C, Geinhofer S. "Network densification: The dominant theme for wireless evolution into 5G". IEEE Communications Magazine, 52(2), 82-89, 2014.

[8] Andrews JG, Buzzi S, Choi W, Hanly SV, Lozano A, Soong ACK, Zhang JC, "What Will 5G Be?". IEEE Journal on Selected Areas in Communications, 32(6), 1065-1082, 2014.

[9] 3GPP. "ETSI Summit on Future Mobile and Standards for 5G". http://www.3gpp.org/news-events/conferences/ 1515-etsi-summit-on-future-mobile-and (11.04.2018).

[10] Shakir MZ, Qarage KA, Tabassum H, Aloini MA, Serpedin E, Imran MA. "Green heterogeneous small-cell networks: Toward reducing the $\mathrm{CO}_{2}$ emissions of mobile communications industry using uplink power adaptation". IEEE Communications Magazine, 51(6), 52-61, 2013.
[11] Luo S, Zhang R, Lim TJ. "Optimal power and range adaptation for green broadcasting". IEEE Transactions on Wireless Communications, 12(9), 4592-4603, 2013.

[12] Vereecken W, Deruyck M, Colle D, Joseph W. Pickavet M., Martens L., Demeester P. "Evaluation of the potential for energy saving in macrocell and femtocell networks using a heuristic introducing sleep modes in base stations". EURASIP Journal on Wireless Communications and Networking, 170, 1-14, 2012.

[13] Cai S, Che Y, Duan L, Wang J, Zhou S, Zhang R. "Green 5G heterogeneous networks through dynamic small-cell operation". IEEE Journal on Selected Areas in Communications, 34(5), 1103-1115, 2016.

[14] Details are hidden under the double-sided privacy policy.

[15] Li L, Peng M, Yang, C, Wu Y. "Optimization of base-station density for high energy-efficient cellular networks with sleeping strategies". IEEE Transactions on Vehicular Technology, 65(9), 7501-7514, 2016.

[16] Namdar M, Ilhan H, Durak-Ata L. "Dispersed chirp-z transform based spectrum sensing and utilization in cognitive radio networks". IET Signal Processing, 8(4), 320-329, 2014.

[17] Che YL, Duan L, Zhang R. "Spatial throughput maximization of wireless powered communication networks". IEEE Journal on Selected Areas in Communication, 33(8), 1534-1548, 2015.

[18] Samarakoon S, Bennis M, Saad W, Debbah M, Latva-aho M. "Ultra dense small cell networks: turning density into energy efficiency". IEEE Journal on Selected Areas in Communications, 34(5), 1267-1280, 2016.

[19] "Small cell enhancements for E-UTRA and E-UTRAN Physical layer aspects". $3^{\text {rd }}$ Generation Partnership Project (3GPP), TR 36.872, 2013. 